\title{
Research article \\ Validation of a simple formula for calculation of serum chloride with estimated value using ion selective electrode
}

\author{
Manisha K., Ashok Prabhu, Sowndarya K., Sudha K. \\ Department of Biochemistry, Kasturba Medical College, Mangalore, Manipal Academy of Higher Education, Manipal, \\ Karnataka, India
}

(Received: April $2021 \quad$ Revised: May $2021 \quad$ Accepted: June 2021)

Corresponding author: Sudha K. Email: sudha.k@manipal.edu

\begin{abstract}
Introduction and Aim: The maintenance of fluid balance in the intracellular and extracellular compartmentsis by two major electrolytes, namelysodium and chloride. An increase in sodium is associated with an increase in chloride level and vice versa. The normal reference ranges of sodium and chloride in blood differ by $40 \mathrm{mmol} / \mathrm{L} . \mathrm{On}$ this basis, chloride values can be calculated manually by subtracting 40 from the estimated sodium value.

Methods: The study population included 150 normal subjects and 150 diabetic patients.Sodium and chloride, as estimated by the ISE method, were noted in 75 random and fasting samples of diabetic group and non-diabetic group. Chloride values were calculated by the new formula(Serumchloride=Serumsodium-40). Mean values of chloride obtained by estimation and calculation were then compared in both diabetics and normal controls. Correlation analysis of estimated chloride and calculated chloride was done by Pearson's correlation.

Results: Chloride determined by the ISE method showed a statistically significant positive correlation with calculated value both in normal and diabetic groups. Further,estimated chloride and calculated chloride values were comparable within the groups in controls and diabetics irrespective of the type of sample collected, ther $>0.95$, $\mathrm{p}=0.0001$ in fasting samples of both groups and $\mathrm{r}=0.899, \mathrm{p}=0.0001$ in random samples of both groups. The percentage error calculated between fasting and random samples of both the groups was negligible (less than 1\%) ,clearly indicating the accuracy and reliability of the value obtained by using the new simple formula for chloride estimation.
\end{abstract}

Conclusion: On the availability of estimated sodium, chloride values can be calculated by subtracting forty from the same. The values so obtained are reliable in normal as well as the diabetic state where dysnatremia is common.

Keywords: Calculated chloride; fasting blood sugar (FBS); random blood sugar (RBS); serum electrolytes.

\section{INTRODUCTION}

$\mathrm{I}$ n clinical practice, electrolyte disorders are detected in a broad spectrum of patients from asymptomatic to critically ill and are linked to increased morbidity and mortality (1-3). An increase in sodium is associated with an increase in chloride level and vice versa. Diabetes mellitus (DM) is one of the diseases that exhibits increased frequency of electrolyte disturbances, due to associated acidbase abnormalities and renal malfunction(4). As glucose is an osmotically active substance, hyperglycemia may be followed by dysnatremia (5).Various methods are used for the determination of electrolyte concentration in serum, some of them being- flame atomic emission spectrometry, ion selective electrodemethod (ISE), enzymatic or chemical reactions in spectrophotometric methods (6).

A clinical laboratory requires a method that is simple in technique and that which yields reproducible results with the accuracy of clinical significance. Clinician prefers a method that gives quick results and several clinical parameters like BUN, osmolality, LDL, eGFR are even today reported by many laboratories by calculated methods $(7,8)$. By our experience and critical observation of lab reports, we have derived a simple, reliable formula to estimate chloride in a givenplasma/serum sample whose sodium level is already estimated by ISE.

The present study aims to quantitate and compare serum ISE estimated chloride with calculated chloride and to find if any endogenous factor like glucose interferes with calculated chloride in diabetic patients where dysnatremia is common. The study highlights the utility of this formula in calculating serum chloride in small clinical labs and pass on the financial benefit to the patient.

\section{MATERIALS AND METHODS}

The study population included 150 normal subjects and 150 diabetic patients. Data was collected from the laboratory request form of walk-in patients who came with a request for fasting or random plasma glucose and serum electrolytes. The data was then segregated as a diabetic group and non- diabetic group (75-random samples; 75- fasting samples) in each group.Electrolytes were estimated in serum by the ion-selective electrode method using (ISE Module) of the Roche/Hitachi Cobas C-6000 systems, a fully automated random access analyzer $(9,10)$.Sodium and chloride, as estimated by the ISE 
method, were noted in all samples. For the determination of electrolytes, the sample was diluted $1: 31$, and therefore the activity coefficients were essentially constant. The sodium electrode is based on a neutral carrier, and the chloride electrode is based on an ion exchanger(10). Chloride values were calculated by a simple new formula (serum chloride= serum sodium-40). Mean values of chloride obtained by estimation and calculation were then compared in both diabetics and normal controls. Student pairedttest was used to find the statistical significance of estimated and calculatedchloride. Correlation analysis of estimated chloride and calculated chloride was done by Pearson's correlation, and $\mathrm{p}<0.05$ was considered statistically significant.

\section{RESULTS}

Table 1 indicates the baseline data of the study population. Chloride determined by the ISE method showed a statistically significant positive correlation with calculated value in both normal and diabetic groups. Further, estimated chloride and calculated chloride values were comparable within the groups in controls and diabetics irrespective of the type of sample (random/fasting) collected, the $\mathrm{r}$ value greater than $0.95, p=0.000$ in fasting samples of both groups and $\mathrm{r}=0.899, \mathrm{p}=0.000$ in random samples of both groups (Table $2 \& 3$ ). The percentage error calculated between estimated chloride and calculated chloride in fasting and random samples of both the groups were negligible (less than 1\%), as depicted in table $4 \& 5$, clearly indicating the accuracy and reliability of the value obtained by using the new simple formula for chloride estimation.

Table1: Baseline data of normal and diabetic patients (Mean \pm SD)

$\mathrm{N}=$ Number of samples

\begin{tabular}{|c|c|c|}
\hline Parameters & Normal $(\mathbf{N}=\mathbf{7 5})$ & Diabetes Mellitus $(\mathbf{N}=\mathbf{7 5})$ \\
\hline Fasting blood glucose(mg\%) & $81.45 \pm 10.14$ & $184.33 \pm 3.66$ \\
\hline Random blood glucose (mg\%) & $101.06 \pm 10.12$ & $317.29 \pm 17.93$ \\
\hline Fasting serum sodium(mmol/L) & $139.54 \pm 2.75$ & $137.49 \pm 3.79$ \\
\hline Random serum sodium(mmol/L) & $138.37 \pm 3.41$ & $134.07 \pm 6.36$ \\
\hline
\end{tabular}

Table 2: Correlation of estimated and calculated chloride in fasting serum samples of normal and diabetes mellitus

\begin{tabular}{|c|c|c|c|c|}
\hline Samples & $\begin{array}{c}\text { Estimated Chloride } \\
(\mathbf{m m o l} / \mathbf{L})\end{array}$ & $\begin{array}{c}\text { Calculated Chloride } \\
(\mathbf{m m o l} / \mathbf{L})\end{array}$ & $\begin{array}{c}\mathbf{r} \\
\text { value }\end{array}$ & $\mathbf{p}$ value \\
\hline Normal & $100.05 \pm 2.97$ & $99.28 \pm 2.73$ & 0.958 & 0.000 \\
\hline Diabetes mellitus & $97.86 \pm 3.82$ & $97.49 \pm 3.79$ & 0.974 & 0.000 \\
\hline
\end{tabular}

Table 3: Correlation of estimated and calculated chloride in random samples of normal and diabetes mellitus

\begin{tabular}{|c|c|c|c|c|}
\hline Samples & $\begin{array}{c}\text { Estimated Chloride } \\
(\mathbf{m m o l} / \mathbf{L})\end{array}$ & $\begin{array}{c}\text { Calculated Chloride } \\
(\mathbf{m m o l} / \mathbf{L})\end{array}$ & $\begin{array}{c}\mathbf{r} \\
\text { value }\end{array}$ & $\begin{array}{c}\mathbf{p} \\
\text { value }\end{array}$ \\
\hline Normal & $98.85 \pm 3.48$ & $98.37 \pm 3.41$ & 0.899 & 0.000 \\
\hline Diabetes mellitus & $94.84 \pm 6.44$ & $94.07 \pm 6.36$ & 0.899 & 0.000 \\
\hline
\end{tabular}

Table 4: Comparison of estimated chloride with calculated chloride in fasting serum samples of normal and diabetic patients

\begin{tabular}{|c|c|c|c|c|}
\hline Samples & $\begin{array}{c}\text { Estimated Chloride } \\
(\mathbf{m m o l} / \mathbf{L})\end{array}$ & $\begin{array}{c}\text { Calculated Chloride } \\
(\mathbf{m m o l} / \mathbf{L})\end{array}$ & $\begin{array}{c}\text { \% } \\
\text { error }\end{array}$ & $\begin{array}{c}\mathbf{p} \\
\text { value }\end{array}$ \\
\hline Normal & $100.05 \pm 2.97$ & $99.28 \pm 2.73$ & 1.3 & 0.100 \\
\hline Diabetes mellitus & $97.86 \pm 3.82$ & $97.49 \pm 3.79$ & 0.4 & 0.554 \\
\hline
\end{tabular}

Table 5: Comparison of estimated chloride with calculated chloride in random samples of normal and diabetic patients

\begin{tabular}{|c|c|c|c|c|}
\hline Samples & $\begin{array}{c}\text { Estimated Chloride } \\
(\mathbf{m m o l} / \mathbf{L})\end{array}$ & $\begin{array}{c}\text { Calculated Chloride } \\
(\mathbf{m m o l} / \mathbf{L})\end{array}$ & $\begin{array}{c}\text { \% } \\
\text { error }\end{array}$ & $\begin{array}{c}\mathbf{p} \\
\text { value }\end{array}$ \\
\hline Normal & $98.85 \pm 3.48$ & $98.37 \pm 3.41$ & 0.5 & 0.399 \\
\hline Diabetes mellitus & $94.84 \pm 6.44$ & $94.07 \pm 6.36$ & 0.81 & 0.463 \\
\hline
\end{tabular}

\section{DISCUSSION}

Electrolyte disorders are mainly encountered in a broad spectrum of patients from asymptomatic to critically ill and arelinked to increased morbidity and mortality (1-3). An increase in plasma sodium is associated with an increase in chloride level and vice versa. The normal reference ranges of plasma/serum sodium and chloride differ by $40 \mathrm{mmol} / \mathrm{L}$. With this knowledge, chloride values can be calculated manually by subtracting 40 from the estimated sodium value. The reference range in our laboratoryis 136 - 149mmoles/L for sodium and 96$109 \mathrm{mmoles} / \mathrm{L}$ for chloride. The range of chloride levelobtained by calculation using the formula 
[plasma chloride $=$ plasma sodium -40 ] will also be $96-109 \mathrm{mmoles} / \mathrm{L}$. It can be seen that the reference range of chloride estimated by ISE matches with the calculated values.As seen from the results, there is absolutely no difference between estimated and calculated chloride values in both fasting and random samples of normal individuals and diabetics. Variability between methods of estimation becomes insignificant in the case of chloride due to the wide range of normal values. However, whichever method is used it must reflect the interindividual variability. Student paired ' $t$ ' test used in the study takes care of this fact.We considered diabetics in the study just to see if other factors like glucose present in the sample have any effect on calculated chloride values compared to that got from the ISE method. Diabetes mellitus is one of the diseases with increased frequency of electrolyte abnormalities as it is associated with acid base disturbances and renal malfunction. Hyperglycemia is associated with a decrease in serum sodium concentration (5). In hyperglycemia, water moves from the intracellular fluid (ICF) to the extracellular fluid (ECF) along the osmotic gradient, as glucose cannot enter all cells freely (11). A study conducted on diabetic patients of Saudi Arabia, reported a significant reduction in serum sodium levels among types I or II diabetic patients especially among insulin-treated patients (12). Serum sodium level decreases as fasting blood glucose increases in diabetes mellitus and osmotic diuresis is the cause of dysnatremia (13). Thus, diabetes mellitus is associated with either hyponatremia or hypernatremia based on the hyperglycemic state, which tends to shift serum sodium to opposite directions. The study demonstrates the efficacy of formula for calculation of serum chloride not only in normal but even abnormal conditions like diabetes mellitus. Osmotically active compounds like glucose were not a confounding factor for the calculation of chloride in the current study. However, marked hypertriglyceridemia, due to light scattering effects can produce overestimation of serum chloride (14). Similarly, serum iodide can also interfere with chloride estimation (15). Further, there can be a more pronounced elevation in chloride concentration, with the use of ISE than with other methods $(16,17)$. Therefore, it is worthwhile to determine serum chloride by calculation.

Correlation studies of calculated and estimated serum chloride indicate that even in diseased conditions like diabetes mellitus where sodium levels alter, the calculated chloride value remained the same as the estimated value. Further, the calculated value did not alter even with the type of sample (random/fasting) both in normal and diabetic samples. The percentage of error between the calculated and estimated chloride was less than $1 \%$ in normal and diabetes patients. The results of the studyproves that the new formula for calculation of chloride is an equally reliable method as ion selective method, in samples whose sodium is determined by ISE method. In clinical laboratories, estimation of chloride by ISE involves calibration cost and expenditure of regularreplacement of the electrode. Because of the emphasis on cost containment, use of simple fomula to calculate serum chloride gains importance. The formula for calculation of serum/plasma chloride will not onlybe cost effective but proves to be accurate to take correct clinical decisions.

\section{CONCLUSION}

To the best of our knowledge, no study has been performed to calculate chloride from sodium value.The study definitely highlights the utility of this formula for calculation of serum chloride in small clinical labs and pass on the financial benefit to the patient.

\section{CONFLICT OF INTEREST}

Authors declare no conflict of interest.

\section{REFERENCES}

1. Corey, H. E. The anion gap:studies in the nephrotic syndrome anddiabetic ketoacidosis. J Lab Clin Med. 2006; 147: 121-125.

2. Oh, M. S., Carroll, H. J., Uribarri, J. Mechanism of normochloremic and hyperchloremic acidosis in diabetic ketoacidosis. Nephron. 1990; 54:1-6.

3. Haterill, M.,Waggie, Z., Purves, L., Reynolds, L., Argent, A. Mortality and the nature of metabolic acidosis in children with shock. Intensive care Med. 2003; 29:286-291.

4. Nasri, H., Rafiean, K. M. Diabetes mellitus and renal failure: Prevention and management. J Res Med Sci. 2015; 20(11): 1112-1120.

5. Matz, R. Hyponatremia: evaluating the correction factor for hyperglycemia.Am J Med. 2000; 108: 180-181.

6. Burnett, R. W, Covington, A. K., Fogh-Andersen, N., Külpmann, W. R., Lewenstam, A., Maas, A. H., et al., Recommendations for measurement of and conventions for reporting sodium and potassium by ion-selective electrodes in undiluted serum, plasma or whole blood. International Federation of Clinical Chemistry and Laboratory Medicine (IFCC). IFCC Scientific Division Working Group on Selective Electrodes. Clin Chem Lab Med. 2000; 38: 10651071.

7. Sudha, K., Aradhana, M., Afzal,A., Charu, Y.Validation of Freidwalds formula in pre and postmenopausal women: an Indian perspective study. Biomedicine. 2017; 37(1): 026031.

8. Reshma, K., Sudha, K., Mamatha, S. Association of prostate disorders with renal dysfunction: Role of biochemical markers. Int J Pharm Bio Sci 2014; 5(4): (B) 704-708.

9. Khalil, A. H. S., Moody, G. J., Thomas, J. D. R. Ion selective electrode determination of sodium and potassium in blood and urine. Clinical Analysis and Analytical Biochemistry. 1986; 19(17-18): 1809-1830.

10. Burnett, R. W., Covington, A. K., Foqh, A. N., Kulpmann, W. R., Lewenstam, A., Maas, A. H. J., et al., Use of ion selective electrode for blood electrolyte analysis. Recommendations for nomenclature, definitions and conventions. Clin Chem Lab Med2000; 38(4): 363-370.

11. Caduff, A., Lutz, H. U. Dynamics of blood electrolytes in repeated hyper and/or hypo glycaemic events in patients with type 1 diabetes. Diabetologia. 2011; 54: 2678-2689. 
12. Khalid, Al-R., Khalid, S. Correlation between serum electrolytes and fasting glucose and $\mathrm{Hb} 1 \mathrm{Ac}$ in Saudi Diabetic Patients. Biol Trace Elem Res.2011; 144:463-468.

13. Khan, R. N., Saba, F., Kausar, S. F., Siddiqui, M. H. Pattern of electrolyte imbalance in Type 2 diabetes patients: Experience from a tertiary care hospital. Pak J Med Sci. 2019; 35(3): 797-801.

14. Vader, H. L., Vink, C. L. J. The influence of viscosity on dilutionmethods: Its problems in the determination of serum sodium.ClinChim Acta. 1975: 65; 379-388.

15. Fischman, R. A., Fairclough, G. F., Cheigh, J. S. Iodide and negativeanion gap. N Engl J Med. 1978; 29: 1035-1036.

16. Wacks, I., Oster, J. R., Perez, G. O., Kett, D. H. Spurious hyperchloremia and hyperbicarbonatemia in a patient receiving pyridostigmine bromide therapy for myasthenia gravis. Am JKidney Dis. 1990; 16: 76-79.

17. Kraut, J. A., Madias, E. N. Serum anion gap: its uses and limitations in clinical medicine. Clin J Am Soc Nephrol, 2007; 2: 162-174. 